\section{Is It Ethical for Health Care Organizations to Charge Institutions for Experiential Rotations?}

\section{THE "PRO" SIDE}

When a service is highly valued, there is an expectation that the service will be preserved. Such preservation should be closely scrutinized to ensure alignment with ethical principles. The value of experiential rotations in pharmacy is not in question, but their viability, integrity, accessibility, and sustainability are key considerations in answering the question posed here. When a service is subsidized by students and government, there is an expectation that all providers of that service will be adequately compensated. Yet health care organizations that host experiential student rotations are not properly funded to provide this service. The educational institutions partially reimburse the health care organizations with "honoraria", but these payments do not cover the full cost of the rotations. Being ethical means conforming to accepted standards that are consistent with agreed-upon principles of correct moral conduct. Adequate reimbursement for services provided is one such principle of moral conduct. Therefore, it is ethical for health care organizations to charge educational institutions for experiential student rotations.

\section{Evidence}

In this time of strict budgets and increasing costs, ${ }^{1}$ health care organizations are juggling priorities to meet the demands of patient care. Efforts to improve productivity, allocate resources appropriately, and optimize staffing, while staying within budget, are paramount, but the success of such efforts varies. For example, the Vancouver Coastal Health Authority, in its statement of operations for 2007/2008, reported that expenditures for the preceding year had exceeded revenues by $\$ 28$ million. ${ }^{2}$

Students consume resources while on rotation, mostly through the preceptor's lost productivity in direct patient care. In a study performed at the College of Pharmacy and Health Sciences of Drake University, in Des Moines, Iowa, preceptors spent about $21 \%$ of their time either teaching or supervising their students. ${ }^{3}$ There is a cost to training preceptors and a further cost to displacing them from their operational duties when they are teaching. A workload offset is required to maintain productivity.

The standards of the Canadian Council for Accreditation of Pharmacy Programs specify that undergraduate pharmacy students work for 480 hours in their final experiential rotations, ${ }^{4}$ a requirement that highlights the need to sustain the quantity and quality of these rotations. The 2005 Summit to Advance Experiential Education in Pharmacy, sponsored by the American Association of Colleges of Pharmacy and the Academic Practice Partnership Initiative, identified some barriers to optimal experiential rotations, including "lack of reimbursement to site for experiential education efforts, . . . and site's lack of ability to provide enough staff members to aid with students' learning".

Health care organizations are not directly funded to instruct students. At Vancouver Coastal Health - Providence Health Care, the direct cost of preceptors (i.e., the preceptors' hourly wages) for a 4-week rotation for one resident or undergraduate student is about $\$ 1200$ (Peter Loewen, Vancouver Coastal Health, personal communication, September 23, 2008). Currently, honoraria alone do not offset this expense; however, these direct costs are offset to some degree by indirect and sometimes intangible benefits to the institution ${ }^{6}$ (Peter Loewen, Vancouver Coastal Health, personal communication, September 23, 2008).

Sustainability means more than ensuring financial stability. For instance, the Commission on the Future of Health Care in Canada (the Romanow Commission) defined sustainability as "ensuring that sufficient resources are available over the long term to provide timely access to quality services that address Canadians' evolving health needs." 7 These resources include "the required health care providers and the physical resources (facilities, equipment, technology, research and data) that are needed to provide the range of services offered." To this end, efforts to increase enrolment in educational institutions as a way to address the pharmacist shortage and to provide adequate numbers of preceptors for future students are imperative.

A survey by the British Columbia Branch of the Canadian Society of Hospital Pharmacists (CSHP) in 2005 found that $87 \%$ of hospitals in that province had at least one pharmacist vacancy. ${ }^{8}$ The shortage of pharmacists, particularly those with residency training, has limited the number of suitably skilled preceptors who are available. Furthermore, as pharmacy faculties push to increase enrolment to alleviate the shortage of pharmacists, there is increased pressure for health authorities to train more students. In its 2005-2009 strategic plan, ${ }^{9}$ the Faculty of Pharmaceutical Sciences at the University of British Columbia (UBC) proposed to double enrolment over the 5 years starting in 2005, in part by expanding the program to the Okanagan campus in Kelowna; this increase in enrolment is anticipated to be complete by 2010 . Initiatives to increase enrolment have also been announced in the most recent strategic plans of the schools of pharmacy at University of Toronto ${ }^{10}$ and the University of Manitoba. ${ }^{11}$ These objectives will mean an imminent demand for more rotations in health care organizations. 
Although educational institutions recognize these experiential services in a perfunctory manner by providing honoraria, the next step is to formally acknowledge the services through a more realistic cost recovery model, such as the development of fee schedules. In hospital practice, the concept of funding for service through the program management model is common practice and a step closer to sustainability. Proper funding would facilitate dedicated resources for appropriate preceptor "back-fill", thus minimizing the operational impact. Adequate funding would also enable pharmacists to fulfill their responsibility to contribute to their own professional development as well as that of students and colleagues, as outlined in the Framework of Professional Practice of the College of Pharmacists of British Columbia. ${ }^{12}$ Furthermore, a portion of the reimbursement could be allocated to staff for attending conferences and delivering presentations, which would enhance the quality of preceptors and subsequently the education level of the department. This arrangement benefits the student, the practising pharmacist, and the patient.

Given the high demand for pharmacists and the current movement to have practising pharmacists provide increased clinical services, experiential rotations are integral as preparation for the pharmacy profession. UBC collects tuition and receives government subsidies for the purpose of educating students. If the university in effect outsources some of that education to a hospital, then ethical principles dictate that they should reimburse the health care organization. The UBC Faculty of Pharmaceutical Sciences has grounds to lobby the university to increase funding for these rotations. UBC reported excess revenues of $\$ 4.2$ million over expenses at the end of the first quarter of 2008, and the BC government contributed over $\$ 200$ million to the university during the first quarter alone. ${ }^{13}$ Since both UBC and the British Columbia Health Authorities receive the majority of their funding from the government, it is ethical for the university to reimburse the health authority for services rendered.

\section{References}

1. Don Avison, chair. Report of the Pharmaceutical Task Force to the Honourable George Abbott, Minister of Health, Province of British Columbia. Victoria (BC): The Task Force; 2008 Apr [cited 2008 Sep 18] Available from:http://www.health.gov.bc.ca/library/publications/year/2008/ PharmaceuticalTaskForceReport.pdf

2. Goodreau I, Campbell D. Financial statements of Vancouver Coastal Health Authority year ended March 31, 2008. Vancouver (BC): Vancouver Coastal Health Authority; 2008 [cited 2008 Sep 23]. Available from: http://www.fin.gov.bc.ca/ocg/pa/07_08/Sup\%20E/pdf/Van_Coastal_Hlth _Auth_Fin_Stmts.pdf

3. Selander LK, Larson LN. Economic costs and benefits associated with a community pharmacy rotation. Am J Pharm Educ 1995;59(1):7-14.

4. Guideline 10.3. In: Accreditation standards and guidelines for the baccalaureate degree program in pharmacy. Vancouver (BC): Canadian Council for Accreditation of Pharmacy Programs; revised 2006 [cited 2008 Sep 18]. Available from: http://www.ccapp-accredit.ca/standards/

5. O’Sullivan T, Hammer DP, Manolakis PG, Skelton JB, Weber SS, Dawson $\mathrm{KN}$, et al. Pharmacy experiential education present and future: realizing the Janus vision [background paper]. American Association of Colleges of Pharmacy and Academic Practice Partnership Initiative Summit to Advance Experiential Education in Pharmacy. Chicago (IL): American Association of Colleges of Pharmacy; 2005 Jun 3 [cited 2008 Sep 18]. Available from: http://courses.washington.edu/pharm560/APPI/APPIRelationships.html
6. Draugalis JR, Carter JT, Slack MK. Curricular and financial implications of PharmD clerkship placements. Am J Pharm Educ 1996;60 (2):146-151.

7. Romanow RJ, chair; Commission on the Future of Health Care in Canada. Building on values: the future of health care in Canada. Final report. Saskatoon (SK): The Commission; 2002 [cited 2008 Sep 18]. p 36-37. Available from: http://www.hc-sc.gc.ca/hcs-sss/hhr-rhs/strateg/romanow-eng.php

8. Pharmacist shortage survey 2005. Vancouver (BC): Canadian Society of Hospital Pharmacists, British Columbia Branch; 2005 [cited 2008 Sep 23]. Available from: http://www.cshp-bc.com/publications/Pharmacist_ shortage_2005.pdf

9. 2005-2009 strategic plan. Vancouver (BC): University of British Columbia, Faculty of Pharmaceutical Sciences; 2005 [cited 2008 Sep 23]. Available from: http://www.pharmacy.ubc.ca/about_us/linked_documents/ Strategic_Plan.pdf

10. Strategic plan 2004. Toronto (ON): University of Toronto, Leslie Dan Faculty of Pharmacy; 2004 [cited 2008 Sep 23]. Available from: http://www.pharmacy.utoronto.ca/about/files/StrategicPlan_2004_June20.pdf

11. Strategic plan 2006-2011. Winnipeg (MB): University of Manitoba, Faculty of Pharmacy; 2006 [cited 2008 Sep 23]. Available from: http:// www.umanitoba.ca/faculties/pharmacy/Basic_PDF/Strategic_Plan_2011.pdf

12. Framework of professional practice. Vancouver (BC): College of Pharmacists of British Columbia; [cited 2009 Jun 25]. Available from: http://www.bcpharmacists.org/library/D-Legislation_Standards/ D-2_Provincial_Legislation/1009- FPP.pdf

13. First quarter fiscal 2008-2009. Audit Committee report for the three months ended June 30 2008. Vancouver (BC): University of British Columbia; 2008 [cited 2008 Sep 23]. Available from: http:// www.finance.ubc.ca/documents/Reporting/FIRST\%20QUARTER\% 20FISCAL\%202008-2009\%20(Finance\%20website).pdf

\author{
Arden Barry, BSC, BSc(Pharm), ACPR \\ Nicole Bruchet, BSC, BSC(Pharm), ACPR \\ Jennifer Kendrick, BSC, BSC(Pharm), ACPR \\ Leanne Kwan, BSC(Pharm), ACPR \\ PharmD Students \\ Sam Louie, BSc (Pharm) \\ Adjunct Professor \\ Faculty of Pharmaceutical Sciences \\ University of British Columbia \\ Vancouver, British Columbia
}

Jennifer Kendrick is also a Clinical Pharmacist with the BC Children's Hospital and Leanne Kwan is also a Clinical Pharmacist with St Paul's Hospital, Vancouver, British Columbia.

\section{THE "CON" SIDE}

In Canada, all pharmacy students, residents, and doctor of pharmacy students are required to perform experiential rotations within our health care organizations to satisfy the requirements of their respective accredited programs. Levying a charge for these rotations may limit the number of students that educational institutions can afford to train. It might also drive up the cost of tuition fees, further restricting the people who can apply for these programs. Ultimately, charging for such rotations contravenes the true meaning of the term "professional" and is against the code of ethics to which we agreed when we became licensed as pharmacists. 
A professional is considered "to have extensive theoretical knowledge ... and to possess skills based on that knowledge that they are able to apply in practice." They are regulated by "bodies with [the] powers to admit and discipline members, and [have] some degree of monopoly rights."' 1 The Manitoba Pharmaceutical Association's Code of Ethics states that "a pharmacist shall be a willing, sincere and diligent preceptor in the training and education of future pharmacists." ${ }^{2}$ The Alberta College of Pharmacists' Code of Ethics states that pharmacists should "nurture the profession" by "contribut[ing] to the future of the profession by participating in the education of provisional pharmacists and technicians and students". ${ }^{3}$ In the province of Saskatchewan, pharmacy graduates recite the Oath of Maimonides, which dates back to the 12th century. Moses Maimonides' oath reads, in part, "May the love for my art actuate me at all time; may neither avarice nor miserliness, nor thirst for glory or for a great reputation engage my mind; for the enemies of truth and philanthropy could easily deceive me and make me forgetful of my lofty aim of doing good to Thy children." These words demonstrate that since as far back as the 12 th century, those in a helping profession have vowed to assist in training those who follow them, without asking for anything in return.

Health care organizations receive many benefits from having their professional staff members serve as preceptors for students. These benefits extend well beyond those of monetary value. Precepting increases job satisfaction and creates a sense of giving back to the profession. In a survey of 185 community physicians who offered primary care rotations to medical students, $82 \%$ of respondents reported an increase in their enjoyment of the practice of medicine, $66 \%$ had the desire to keep up with recent developments in their profession, and $44 \%$ reported an increase in patients' perception of their stature..$^{5}$ A similar survey of physicians, nurses, and pharmacists indicated that teaching students had a positive impact on overall job satisfaction for $83 \%$ of respondents. ${ }^{6}$ In the same survey, the most highly valued incentives to teaching included continuing medical education credits for teaching, no-cost access to online library resources, and continuing education and university academic appointments; financial compensation was ranked fifth. ${ }^{6}$ Offering preceptorships may also assist with recruitment and retention, as this activity allows individual departments to showcase their strengths and opportunities within their respective hospitals or health regions. ${ }^{78}$ In a 2005 editorial on the joys of precepting, Ensom commented that this activity offers opportunities to "[contribute] to a pharmacy student's or resident's professional development and, years later, [to see] the visible fruits of one's labour." If every pharmacy professional were to embrace his or her respective code of ethics, it might be possible to increase the number of rotation sites, allowing for expansion of enrolment at our pharmacy schools.

Students not only increase job satisfaction for those working in the organization, they also inject a certain creativity and innovation into the pharmacist's clinical practice. In fact, the preceptor often learns from the student's questions and unique perspectives. It has been said that "to teach is to learn twice", since one must understand something comprehensively before teaching it to someone else; this principle allows our preceptors to become better practitioners. Students have also been shown to benefit patient care. In a 3-year study on an internal medicine ward, doctor of pharmacy students contributed to $28.8 \%$ of all pharmacy interventions, of which $92 \%$ were accepted by the internal medicine team and $49.5 \%$ were of moderate-to-high impact (those that decrease the risk of death or prevent a life-threatening complication, reduce the length of hospital stay, minimize treatment failure, or decrease the risks of moderate adverse effects). ${ }^{10}$ Students also contribute to research projects and continuing education in the form of journal clubs and case presentations for both pharmacy and the allied health care team.

The current practice at the University of British Columbia Faculty of Pharmaceutical Sciences is to provide "honoraria", along with certificates or preceptor awards, as a means of recognizing those involved in students' experiential learning. These tokens of appreciation are by no means considered financial reimbursements for the services that these preceptors provide. In most instances, the funds are not incorporated into departmental operating budgets, but instead are placed in a departmental educational fund earmarked for further continuing education for department staff members. The amounts are set by the educational institutions, whereby the monies provided are based on the availability of funding within the current university budget and tuition limitations. If this system were changed to one in which the amount was set by the health care organizations, we can easily envision a shift in philosophy to revenue generation, instead of welcoming students in the spirit of teaching. Health care in Canada is a nonprofit venture that is funded by the taxpayer, as is a portion of postsecondary education. If health care organizations were to establish a cost for accepting students in experiential rotations, we could find ourselves "robbing from Peter to pay Paul". Let us not forget that Canadian teaching hospitals are funded so as to be able to train students from all health care disciplines, by virtue of their staffing ratios relative to those of community-based facilities,. ${ }^{11}$

If the cost of arranging rotations for students increases, this increase will be passed along to students through increases in already disproportionately high tuition fees. The Canadian Federation of Students has stated that the increasing costs of programs for students must be covered either through an increase in tuition or by cutting other programs, as there has been no increase in government funding. ${ }^{12}$ The gap between rising tuition and the average Canadian wage has been expanding and is now limiting the number of potential applicants. ${ }^{13} \mathrm{~A}$ Canadian survey in 2002 found that $70 \%$ of respondents cited financial reasons for their decision to not attend a postsecondary institution. ${ }^{14}$ The medical community has found that no matter how sharply tuition rises for medical schools, enrolment has not declined, because there are large numbers of excess applicants each year. When tuition increases, well-qualified but less affluent applicants have opted not to apply, which increases the acceptance rate for less well qualified applicants. ${ }^{15}$ Financial barriers also limit the 
experiential learning of students, residents, and doctor of pharmacy students.

Ultimately, we should not forget what led us to the profession of pharmacy, so that we can pass this motivation on to those now entering the profession. We need to continue to take responsibility for the training and mentorship of those who come after us. These individuals will become the leaders of tomorrow. We should not limit their opportunities by contributing to increases in their tuition costs. As pharmacists and professionals, we took an oath to assist in the training of our students. We must therefore ensure that the number of rotation sites available is not limited by cost.

\section{References}

1. Profession. In: Wikipedia, the free encyclopedia. San Francisco (CA) Wikimedia Foundation Inc; [cited 2009 Jun 23]. Available from: http://en.wikipedia.org/wiki/Profession

2. Code of ethics. Winnipeg (MB): Manitoba Pharmaceutical Association; [cited 2009 Jun 23]. Available from: http://www.napra.ca/ Content_Files/Files/Manitoba/current\%20web\%20site/code_of_ethics. pdf

3. Code of ethics. Edmonton (AB): Alberta College of Pharmacists; 2008 [cited 2008 Sep 22]. Available from: https://pharmacists.ab.ca/ nPharmacistResources/CodeofEthics.aspx

4. A quickie on the oath of Maimonides. In: The random thoughts of Louis Schmier [blog]. Published by Louis Schmier; 2007 [cited 2008 Nov 23]. Available from: http://therandomthoughts.edublogs.org/ 2007/08/10/a-quickie-on-the-oath-of-maimonides/

5. Grayson MS, Klein M, Lugo J, Visintainer P. Benefits and costs to community-based physicians teaching primary care to medical students. J Gen Intern Med 1998;13(7):485-488.

6. Latessa R, Beaty N, Landis S, Colvin G, Janes C. The satisfaction, motivation, and future of community preceptors: the North Carolina experience. Acad Med 2007;82(7):698-703.

7. Ensom RJ. Should service contracts be invoked after completion of a hospital pharmacy residency program? The "pro" side. Can J Hosp Pharm 2008;61(4):278-279.

8. Koleba T. Should service contracts be invoked after completion of a hospital pharmacy residency program? The "con" side. Can J Hosp Pharm 2008;61(4):279-280.

9. Ensom MHH. Joys of precepting: lessons learned [editorial]. Can J Hosp Pharm 2005;58(2):59-60.

10. Pham DQ. Evaluating the impact of clinical interventions by PharmD students on internal medicine clerkships: the results of a 3 year study. Ann Pharmacother 2006;40(9):1541-1545.

11. Babich M. Human resources. In: Babich M, Bussières JF, Hall KW, Harding J, Johnson N, Lefebvre P, et al., editors. 2005/06 annual report-hospital pharmacy in Canada. Eli Lilly Canada; 2006 [cited 2009 Jan 5]. p 48-57 Available from:http://www.lillyhospitalsurvey.ca/ hpc2/content/2006_report/humanresouces.pdf
12. Tuition fees in Canada: a pan-Canadian perspective on paying more and getting less. Ottawa (ON): Canadian Federation of Students; [cited 2008 Sep 22]. Available from: http://www.cfs-fcee.ca/html/english/ research/factsheets/factsheet-tuitionfees-8x11.pdf

13. Real fees at historical high. CAUT Rep 2002 Oct [cited 2008 Sep 22];49(8). Published by Canadian Association of University Teachers. Available from: http://www.cautbulletin.ca/en_article.asp?SectionID $=608 \&$ SectionName $=$ News $\&$ VolID $=159 \&$ VolumeName $=$ No\% $208 \&$ VolumeStartDate $=10 / 1 / 2002 \&$ EditionID $=19 \&$ EditionName $=$ Vol $\% 2$ 049\&EditionStartDate $=1 / 1 / 2002 \&$ ArticleID $=1407$

14. Bowlby JW, McMullen K. At a crossroads: first results for the 18 to 20year-old cohort of the Youth in Transition Survey. Ottawa (ON): Human Resources Development Canada and Statistics Canada; 2002 Jan [cited 2008 Sep 22]. Available from: http://www.statcan.ca/english/ freepub/81-591-XIE/81-591-XIE2000001.pdf

15. Kane T. The price of admission: rethinking how Americans pay for college. Berkeley (CA): University of California Press; 1999.

Sally Man, BScH, BSc(Pharm), ACPR

Cesilia Nishi, BSC(Pharm), ACPR

Jerrold Perrott, BSC(Pharm), ACPR

Joanie Tulloch, BSP, ACPR

PharmD Students

Dawn Dalen, BSP, ACPR, PharmD

Clinical Assistant Professor

Faculty of Pharmaceutical Sciences

University of British Columbia

Vancouver, British Columbia

Dawn Dalen is also the Regional Pharmacy Practice Coordinator, Interior Health Authority, Kelowna General Hospital Pharmacy Services, Kelowna, British Columbia.

The Pro and Con articles for this issue's "Point Counterpoint" column were developed from a debate held in fall 2008 as part of the course Advanced Pharmacy Administration Topics in Contemporary Practice, in the Doctor of Pharmacy program at the University of British Columbia. 